\title{
Neuroleptic Malignant Syndrome in Children with Autism Spectrum Disorder (ASD): A Case Report and Brief Review of Recent Literature
}

\author{
Stefano Berloffa ${ }^{1}$, Claudia Dosi ${ }^{1}$, Benedetta Tascini ${ }^{2}$, Beatrice Fossati ${ }^{1}$, Ilaria Lupetti ${ }^{1}$ and Gabriele Masi ${ }^{1, *}$ \\ 1 IRCCS Stella Maris, Scientific Institute of Child Neurology and Psychiatry, 56128 Pisa, Italy; \\ stefano.berloffa@fsm.unipi.it (S.B.); dosiclaudia@gmail.com (C.D.); beatrice.fossati@fsm.unipi.it (B.F.); \\ ilarial.89@otmail.it (I.L.) \\ 2 Department of Woman's and Children's Health, Padua University Hospital, 35128 Padua, Italy; \\ benedetta.tascini@aopd.veneto.it \\ * Correspondence: gabriele.masi@fsm.unipi.it; Tel.: +39-050-886219; Fax: +39-050-886247
}

\section{check for} updates

Citation: Berloffa, S.; Dosi, C.; Tascini, B.; Fossati, B.; Lupetti, I.; Masi, G. Neuroleptic Malignant Syndrome in Children with Autism Spectrum Disorder (ASD): A Case Report and Brief Review of Recent Literature. Children 2021, 8, 1201. https://doi.org/10.3390/ children8121201

Academic Editor: Francisco Alcantud-Marín

Received: 1 November 2021 Accepted: 16 December 2021 Published: 18 December 2021

Publisher's Note: MDPI stays neutral with regard to jurisdictional claims in published maps and institutional affiliations.

Copyright: (c) 2021 by the authors. Licensee MDPI, Basel, Switzerland. This article is an open access article distributed under the terms and conditions of the Creative Commons Attribution (CC BY) license (https:// creativecommons.org/licenses/by/ $4.0 /)$.

\begin{abstract}
Neuroleptic malignant syndrome (NMS) is a rare, life-threatening, idiosyncratic adverse reaction to antipsychotic drugs. Despite the increasing rates in the prescription of antipsychotics in pediatric patients with autism spectrum disorder (ASD), little is known about the occurrence and hallmarks of NMS in this specific population. NMS appears to be part of the larger catatonia domain, based on the frequent relationship between ASD and catatonia, on the shared, when not overlapping, clinical features with malignant catatonia, and on the effectiveness of catatonia treatments on the NMS/MC symptoms. The intrinsic difficulties of exploring NMS in ASD in controlled studies accounts for the subsequent lack of available information. Based on recent reports and on our case report, clinical features of NMS in the pediatric ASD population appear to be the same as the non-ASD population. Further studies are needed to confirm these results.
\end{abstract}

Keywords: neuroleptic malignant syndrome (NMS); autism spectrum disorder (ASD); catatonia; pediatric

\section{Introduction}

Neuroleptic malignant syndrome (NMS) is a rare, life-threatening, iatrogenic condition mainly associated with antipsychotic drug use, and is characterized by fever, altered mental status, muscle rigidity, and autonomic dysfunction. Despite an increased medical awareness, many aspects regarding its epidemiology, physiopathology, and nosology remain controversial, and the syndrome continues to be a clinical challenge.

The NMS was first described in 1960 by Delay and colleagues [1], after the introduction of haloperidol to the market in the late 1950s. When second-generation antipsychotics became available, hopes were high that they would be free from the risk of inducing NMS; unfortunately, most atypical antipsychotics (i.e., aripiprazole, risperidone, olanzapine, clozapine, and paliperidone), have been reported over the years to be associated with NMS, as well as typical AP (i.e., haloperidol, flupentixol, chlorpromazine, and periciazine) [2-4]. Moreover, other classes of drugs have been associated with NMS-like symptoms, such as lithium, carbamazepine, paroxetine, and metoclopramide $[2,3,5]$, following unclear pathways.

Traditionally, NMS is considered to be the result of dopaminergic D2 receptor antagonism or dopamine agonist withdrawal in the central nervous system and spinal cord [6,7], which leads to a cascade of reactions, primarily involving the thermoregulatory center of the hypothalamus, with subsequent hyperthermia, and the basal ganglia, which could explain the motor signs characteristic of this condition, such as rigidity, hypertonia, and tremor. A non-alternative model proposes the concomitant role of toxicity of the muscu- 
loskeletal fibers, supported by the response to dantrolene in NMS and typical antipsychotic drug effects on calcium regulation in skeletal muscular fibers [2].

Over the years, many attempts to standardize diagnostic criteria have been made [8,9], the most recent one by the DSM-5 [10]. NMS is heterogeneous in onset, presentation, course, and outcome. Clinical risk factors for NMS include psychomotor agitation, confusion, disorganized behavior, and catatonia, extrapyramidal signs such as akathisia, while possible pharmacological risk factors are higher dosages, fast titration, and parenteral injections [8,9]. No pathognomonic sign has ever been found. DSM-5 describes the most common clinical features, which include a positive history for dopamine antagonist use (usually within $72 \mathrm{~h}$ prior to symptom development), as hyperthermia, generalized rigidity, described as "lead pipe" in its most severe form, and other neurological and medical symptoms (e.g., tremor, sialorrhea, akinesia, dystonia, trismus, myoclonus, dysarthria, dysphagia, and rhabdomyolysis). They also include, in most cases, changes in mental status, characterized by delirium or altered consciousness (often an early sign), and autonomic instability (tachycardia, diaphoresis, blood pressure elevation or fluctuation, urinary incontinence, and tachypnea). The onset of symptoms varies from hours to days after drug initiation. Underlying pathophysiological mechanisms are still unclear.

The first step in the diagnostic process is to rule out other etiologies including infections, toxin exposure, or metabolic or neurologic causes. Laboratory findings usually include leukocytosis, creatine kinase (CK) elevation of at least four times the upper limit of normal (up to 100,000 IU/L), and decreased serum iron concentrations. CK monitoring not only serves diagnostic purposes, but also for monitoring the condition, since levels of $\mathrm{CK}$ must decrease over time as the condition improves [2]. However, misleading high levels of CK may occur after intramuscular injections, restraints, intense physical activity, or dystonic reactions [11]. Furthermore, a massive asymptomatic CK elevation has been described during antipsychotic exposure in nonpsychotic, drug-naïve youth during treatment with second-generation antipsychotics. In these cases, a drug discontinuation should be considered only when possible signs of NMS or rhabdomyolysis are suspected (i.e., flulike syndrome, fever, weakness, alteration of consciousness, muscle rigidity, tachycardia, hyper-/hypotension, and dark urine) [11].

Autism spectrum disorder (ASD) is a complex neurodevelopmental disorder characterized by persistent deficits in social communication and social interaction across multiple contexts, and restricted, repetitive patterns of behavior, interests, or activities [10]. Pharmacological treatments are commonly used in individuals with ASD to improve associated ASD symptoms such as irritability and agitation, and to treat co-occurring psychiatric conditions such as ADHD, anxiety, depression, bipolar disorder, psychotic symptoms, and other disorders. Although there are currently no rigorous evidence-based guidelines regarding psychotropic medications for children with ASD [12], several randomized controlled trials (RCTs) with antipsychotics in children with ASD have been conducted over the years, mostly risperidone and aripiprazole. Large RCT trials have shown results supporting that both medications are superior to the placebo in alleviating irritability (agitation, anger outbursts, and self-injurious behavior), stereotypy, and hyperactivity $[13,14]$. Few studies are also available concerning other second-generation antipsychotics, [13,15]. Among the first-generation antipsychotics, haloperidol is the most studied and the only one proven to be effective on behavioral symptoms in ASD, although associated with severe side effects [13]. These data have been confirmed by successive RCTs [14,16]. These studies have led to the approval by the U.S. Food and Drug Administration (FDA) and other European medical agencies of two antipsychotic medications, risperidone and aripiprazole, for the treatment of irritability in children with ASD [17].

Currently, there are no known contraindications to using common antipsychotic medications for children with ASD, although some experts believe that atypical responses (e.g., idiosyncratic, disinhibition, or paradoxical reactions) may be more common [12]. Inquiring about previous reactions to medications is often helpful, as may be beginning 
with lower dosages to observe and determine the child's response to the medication [12]. But what do we know about NMS in autistic children?

Recent literature regarding autism and NMS mostly focuses on the association with catatonia and on the treatment with ECT [18,19], given the higher risk for developing catatonia in this population [18]. Clinical features and laboratory findings are comparable to those described in the non-ASD population, as summarized in Tables 1-3.

Table 1. Case reports of pediatric ASD patients with neuroleptic malignant syndrome in the literature: demographic and clinical features.

\begin{tabular}{|c|c|c|c|c|c|c|c|c|}
\hline & AGE & SEX & ASD & ID & AP & $\begin{array}{l}\text { Preceding } \\
\text { Catatonia }\end{array}$ & Other Symptoms & Reference \\
\hline Patient 1 & 17 & $\mathrm{~F}$ & Yes & Yes & $\begin{array}{l}\text { risperidone for } 4.5 \text { years, } \\
\text { haloperidol and ziprasidone as needed }\end{array}$ & Yes & $\begin{array}{l}\text { Restlessness, aggression, mutism, } \\
\text { diaphoresis, sleep disturbances }\end{array}$ & $\begin{array}{l}\text { Ghaziuddin et al., } \\
2017 \text { [18] }\end{array}$ \\
\hline Patient 2 & 12 & M & Yes & Yes & $\begin{array}{c}\text { risperidone, quetiapine, ziprasidone, } \\
\text { olanzapine }\end{array}$ & Yes & $\begin{array}{l}\text { Restlessness, SIB, aggression, } \\
\text { sleep disturbances }\end{array}$ & $\begin{array}{l}\text { Ghaziuddin et al., } \\
2017 \text { [18] }\end{array}$ \\
\hline Patient 3 & 15 & F & Yes & Yes & ziprasidone, chlorpromazine & Yes & Posturing, aggression, mutism & $\begin{array}{l}\text { Ghaziuddin et al., } \\
2017 \text { [18] }\end{array}$ \\
\hline Patient 4 & 9 & M & Yes & Yes & $\begin{array}{c}\text { risperidone } 1.5 \mathrm{mg} / \text { die, loxapine } \mathrm{IM} \\
30 \mathrm{mg} / \mathrm{die}\end{array}$ & Yes & $\begin{array}{l}\text { SIB, aggression, posturing, } \\
\text { anorexia }\end{array}$ & $\begin{array}{l}\text { González-Romero } \\
\text { et al., 2019 [19] }\end{array}$ \\
\hline Patient 5 & 16 & M & Yes & Yes & $\begin{array}{l}\text { aripiprazole } 10 \mathrm{mg} / \text { die, } \\
\text { quetiapine } 250 \mathrm{mg} / \text { die, lorazepam }\end{array}$ & Yes & $\begin{array}{l}\text { Anorexia, asthenia, perioral } \\
\text { myokymia and myoclonus, } \\
\text { difficulty swallowing, polypnea }\end{array}$ & This issue \\
\hline
\end{tabular}

Notes: ASD = autism spectrum disorder; ID = intellective disability; SIB = self-injurious behavior; $\mathrm{AP}$ = antipsychotic.

Table 2. Case reports of pediatric ASD patients with neuroleptic malignant syndrome in the literature: laboratory findings.

\begin{tabular}{|c|c|c|c|c|c|c|c|c|}
\hline & $\begin{array}{l}\text { Blood } \\
\text { Pressure }\end{array}$ & Heart Rate & Fever & $\begin{array}{c}\text { White Blood } \\
\text { Count }\end{array}$ & $\begin{array}{c}\text { AST } \\
\text { (IU/L) }\end{array}$ & $\begin{array}{c}\text { ALT } \\
\text { (IU/L) }\end{array}$ & $\begin{array}{c}\text { CPK } \\
\text { (IU/L) }\end{array}$ & Cerebral MRI \\
\hline Patient 1 & Elevated & Elevated & Yes & Elevated & $195 *$ & $172 *$ & 17,787 * & Normal \\
\hline Patient 2 & Elevated & Elevated & No & Normal & $76^{*}$ & $48^{*}$ & $5993 *$ & Normal \\
\hline Patient 3 & Elevated & Elevated & No & NA & 39 & 23 & 1800 * & $\begin{array}{c}\text { MRI worrisome for } \\
\text { vascular malformation, CT } \\
\text { showed no evidence of } \\
\text { AVM }\end{array}$ \\
\hline Patient 4 & NA & NA & Yes & NA & $409 *$ & $100 *$ & 16,000 * & Normal \\
\hline Patient 5 & Elevated & Elevated & Yes & NA & NA & $72 *$ & NA & Normal \\
\hline
\end{tabular}

Notes: ${ }^{*}$ = abnormal laboratory finding; ALT = alanine transaminase; AST = aspartate transaminase; AVM = atrio ventricular malformation;

$\mathrm{CPK}=$ creatinine phosphokinase enzyme; $\mathrm{EEG}=$ electroencephalogram; $\mathrm{MRI}=$ magnetic resonance imaging; $\mathrm{NA}=$ not available.

Table 3. Case reports of pediatric ASD patients with neuroleptic malignant syndrome in the literature: NMS duration, treatment, and outcomes.

\begin{tabular}{|c|c|c|c|c|}
\hline & Nms Duration & $\begin{array}{l}\text { Non Effective } \\
\text { Tratments }\end{array}$ & Effective Treatments & Outcomes \\
\hline Patient 1 & Months-long & Lorazepam IV & $\begin{array}{l}\text { ECT (total of } 75 \text { ECTs, } \\
\text { during a } 1 \text { year } \\
\text { mainteinance period) }\end{array}$ & $\begin{array}{c}\text { Resolution, no relapses in } 6 \text { years after } \\
\text { discontinuation of ECT }\end{array}$ \\
\hline Patient 2 & 3 months & Lorazepam IV & $\begin{array}{l}\text { ECT (3 years treatment } \\
\text { duration) }\end{array}$ & $\begin{array}{l}2 \text { relapses during previous attempts of } \\
\text { discontinuation of ECT. Ultimately } \\
\text { combined with lorazepam } 32 \mathrm{mg} / \text { die } \\
\text { still ongoing }\end{array}$ \\
\hline Patient 3 & NA & Lorazepam IV & $\begin{array}{l}\text { ECT ( } 3 \text { years treatment } \\
\text { duration, still ongoing) }\end{array}$ & $\begin{array}{l}1 \text { relapses during attempt of } \\
\text { discontinuation of ECT }\end{array}$ \\
\hline Patient 4 & NA & Lorazepam IV & $\begin{array}{l}\text { ECT (1 year treatment } \\
\text { duration, still ongoing) }\end{array}$ & $\begin{array}{c}\text { Positive outcome combined with } \\
\text { behavioral therapy }\end{array}$ \\
\hline Patient 5 & 17 days & / & $\begin{array}{l}\text { Lorazepam IV, combined } \\
\text { with dantrolene and } \\
\text { bromocriptine }\end{array}$ & Resolution, no relapses in 2 years \\
\hline
\end{tabular}


Data on other treatments for catatonia in children with ASD are still lacking, except for a recent case report including two patients successfully treated with clozapine [20].

\section{Case Presentation}

We describe the case of an 18-year-old boy presented with ASD associated with a mild intellectual disability (patient 5 in the tables). Informed consent was obtained from all subjects involved in the study. Regarding the familial load, the paternal uncle presents an anxiety disorder treated with a selective serotonin reuptake inhibitor.

The proband is the first child of unrelated and healthy parents. He attended school with support, had good global functioning and social relationships with classmates, despite his social anxiety, and had progressive improvements in his social skills.

At the age of 13 years old, after his summer break, social isolation acutely worsened, associated with a confusional state, psychomotor agitation, speech impairment, visual hallucinations, cognitive regression, a loss of personal autonomy, and increased anxiety. Quetiapine up to $300 \mathrm{mg} /$ day and alprazolam $0.50 \mathrm{mg} /$ day were prescribed, with complete recovery. Cerebral MRI and metabolic tests were unremarkable. Array-CGH test was not significant, showing a duplication of the long arm of chromosome 6 , inherited from the father.

At the age of 15 years old, the patient had another acute breakdown, which was treated with quetiapine $300 \mathrm{mg}$ /day and had partial recovery (only affective symptoms partly improved) until one year later, when symptoms worsened, with disorganized thought, obsessive symptoms and rumination, catatonic behaviors, associated with asthenia, reduced autonomous mobility, persistent hyporeactivity to stimuli, stiffness in the limbs and hypomymia, apathy, and isolation. Upon initial evaluation in the psychiatric ward, physical examination was unremarkable. Quetiapine was replaced with aripiprazole, with gradual titration, starting with $2.5 \mathrm{mg} /$ day and $2.5 \mathrm{mg}$ increases every 4 days, up to $10 \mathrm{mg} /$ day, with supplementary lorazepam, resulting in a transient improvement in the clinical picture. After 2 days, the boy showed signs of psychomotor retardation, hyperreactivity to stimuli, anorexia, and asthenia. Creatine kinase (CK) was in the normal range when he was discharged.

After 7 days, given the worsening symptoms associated with increased obsessive thoughts, hyperthermia, and CK elevation, the boy was admitted in an emergency department and pharmacotherapy was immediately discontinued. The patient was hospitalized in an intensive care unit for 4 weeks, then in a pediatric ward for 1 week, and finally in our hospital for 10 days. During hospitalization, limb stiffness, perioral myokymia and myoclonus, facial amimia, uncoordinated movements of the tongue and difficulty swallowing, polypnea, tachycardia, and arterial hypertension were observed. Intravenous hydration, dantrolene, clonidine, intravenous benzodiazepines, and carvedilol were administered, followed by bromocriptine therapy and intravenous lorazepam $2 \mathrm{mg} 5$ times a day. A gradual improvement in vigilance, reduction of hypertonus, and resolution of hyperthermia were observed, with gradual motor improvement. After 8 days, blood results showed a reduction in CK (404 U/L, normal CK range $0-50 \mathrm{UI} / \mathrm{mL})$ and a mild increase in liver enzymes (ALT $72 \mathrm{U} / \mathrm{L}$ ).

After being discharged from our hospital, the patient carried out monthly clinical and CPK controls, and after 6 months the patient had a general assessment in our hospital, with persisting control of previous clinical manifestations.

\section{Discussion}

In clinical practice, pharmacological treatments with antipsychotics are commonly used on individuals with ASD to improve associated symptoms such as irritability and agitation. The U.S. Food and Drug Administration and other European medical agencies have approved the use of aripiprazole for the treatment of irritability in autism, bipolar disorder, and schizophrenia in children and adolescents. Results from clinical studies on schizophrenia, bipolar disorder, conduct disorder, and comorbid autism show 
an increased risk of extrapyramidal symptoms when using atypical antipsychotics in children and adolescents, and an increase in akathisia as a common neurological adverse effect in these age groups [21]. The association between antipsychotic drug use on ASD patients and severe adverse events such as NMS is not well understood [22]. Our knowledge on NMS in the autistic pediatric population is still very limited, probably given the intrinsic difficulties of exploring NMS in controlled studies [23]. To the best of our knowledge, no review has ever been published focusing on NMS in an autistic pediatric population. When NMS is involved, case reports remain one of the main sources of information available in the literature.

A challenging issue receiving increased attention, namely in ASD patients, is the relationship between NMS and catatonia. Catatonia is a mood and behavioral disorder characterized by a variety of symptoms such as stupor, catalepsy, waxy flexibility, mutism, negativism, posturing, and other symptoms [10]. Catatonia can occur in the context of a number of diseases, including psychotic and affective disorders, and neurodevelopmental disorders such as ASD seem to be particularly involved [24]. In a recent paper, Fink proposes to bring NMS, as well as other behavioral disorders (delirious mania, self-injurious behavior (SIB) in autism, and limbic encephalitis) within the catatonia tent [25]. This proposal is based on the observation of many common clinical features between those disorders and catatonia. In particular, there is a significant overlap of symptoms between NMS and malignant catatonia (MC), the most severe form of catatonia, associated with autonomic and thermoregulatory dysfunction $[18,26]$. Despite the two terms being sometimes used synonymously, the term NMS is used when there is a documented exposure to antipsychotic drugs. Additionally, NMS and other disorders under the catatonia tent respond well to catatonia treatments, which consist of a high-dose benzodiazepine as a first step, and electroconvulsive therapy (ECT) as a second step. Given these premises, recognizing catatonia assures lifesaving treatments [25]. In these case studies [18], every case of NMS was preceded by catatonic-like symptoms for weeks/months, fueling the ongoing debate about whether NMS is always preceded by catatonia, therefore representing a possible malignant form of catatonia triggered by antipsychotic assumption [27]. However, every patient apparently experienced worsened symptoms with antipsychotic administration after admission.

In a review focused on the adverse events in children and adolescents treated with aripiprazole, the authors highlighted that, despite aripiprazole being considered safe in children, it may cause the same neurological adverse events, such as NMS, as in adults. Furthermore, ASD patients could also develop psychiatric adverse events [28]. Our patient presented a typical NMS clinical picture, confirming that the neuroleptic drugs could also cause NMS in children.

A careful consideration of possible differential diagnoses should include all the conditions with prominent muscle rigidity and/or hyperthermia, such as malignant hyperthermia, malignant catatonia, and heath stroke. All the CNS infections should be ruled out (e.g., meningitis and encephalitis). Drug intoxication and toxicity (e.g., phencyclidine, ecstasy, cocaine, amphetamines, lithium, and baclofen) should also be considered. Serotonin syndrome, characterized by the presence of changes in mental status, agitation, clonus, hyperreflexia, and hyperthermia, with a degree of overlapping clinical presentation, may occur during serotonergic treatments, and the concurrent administration of an antidepressant with an antipsychotic drug may increase the risk of NMS due to serotoninergic transmission interfering with dopaminergic transmission. Progressive encephalomyelitis with rigidity and myoclonus (PERM), suggested to be a more severe variant of the stiff person syndrome, is a rare neurological condition, presenting an alteration of consciousness, cerebellar ataxia, and respiratory insufficiency due to breathing and swallowing difficulties [29].

Therefore, even though this risk should not prevent clinicians from using antipsychotics in severely impaired children and adolescents with ASD, early signs of NMS should be carefully monitored. A timely diagnosis of these signs may be more difficult 
to ascertain when ASD is severe, with mutism and stereotypies, particularly when intellectual disability co-occurs [29], thus in these patients the awareness of possible NMS is particularly important.

Author Contributions: Conceptualization, S.B. and G.M.; methodology, S.B.; investigation, C.D., B.T., B.F., I.L.; data curation, C.D., B.T., B.F., I.L.; writing S.B., C.D.; writing-review and editing, G.M. All authors have read and agreed to the published version of the manuscript.

Funding: Italian Ministry of Health: Ricerca Corrente (Project 2.10: Bipolar spectrum in youth, from cyclothymia to bipolar disorder: clinical and pharmacological implications; GM), and the " 5 per 1000 " voluntary contributions.

Institutional Review Board Statement: Not applicable.

Informed Consent Statement: Written informed consent has been obtained from the patients to publish this paper.

Data Availability Statement: Not applicable.

Conflicts of Interest: Masi was on the advisory boards for Angelini, received institutional research support from Lundbeck and Humana, and was speaker for Angelini and Otsuka. Other authors report no biomedical financial interest or potential conflict of interest.

\section{References}

1. DeLay, J.; Pichot, P.; Lemperiere, T.; Elissalde, B.; Peigne, F. [A non-phenothiazine and non-reserpine major neuroleptic, haloperidol, in the treatment of psychoses]. Ann. Médico-Psychol. Rev. Psychiatr. 1960, 118, 145-152.

2. Tse, L.; Barr, A.; Scarapicchia, V.; Vila-Rodriguez, F. Neuroleptic Malignant Syndrome: A Review from a Clinically Oriented Perspective. Curr. Neuropharmacol. 2015, 13, 395-406. [CrossRef] [PubMed]

3. Oruch, R.; Pryme, I.F.; A Engelsen, B.; Lund, A. Neuroleptic malignant syndrome: An easily overlooked neurologic emergency. Neuropsychiatr. Dis. Treat. 2017, 13, 161-175. [CrossRef]

4. Solmi, M.; Murru, A.; Pacchiarotti, I.; Undurraga, J.; Veronese, N.; Fornaro, M.; Stubbs, B.; Monaco, F.; Vieta, E.; Seeman, M.V.; et al. Safety, tolerability, and risks associated with first- and second-generation antipsychotics: A state-of-the-art clinical review. Ther. Clin. Risk Manag. 2017, 13, 757-777. [CrossRef]

5. Lin, M.L.M.; Robinson, P.D.; Flank, J.; Sung, L.; Dupuis, L.L. The Safety of Metoclopramide in Children: A Systematic Review and Meta-Analysis. Drug Saf. 2016, 39, 675-687. [CrossRef]

6. Velamoor, V.R.; Norman, R.M.G.; Caroff, S.N.; Mann, S.C.; Sullivan, K.A.; Antelo, R.E. Progression of Symptoms in Neuroleptic Malignant Syndrome. J. Nerv. Ment. Dis. 1994, 182, 168-173. [CrossRef]

7. Ware, M.R.; Feller, D.B.; Hall, K.L. Neuroleptic Malignant Syndrome. Prim. Care Companion CNS Disord. 2018, 20, 17r02185. [CrossRef]

8. Levenson, J.L. Neuroleptic malignant syndrome. Am. J. Psychiatry 1985, 142, 1137-1145. [CrossRef]

9. Gurrera, R.J.; Caroff, S.N.; Cohen, A.; Carroll, B.T.; DeRoos, F.; Francis, A.; Frucht, S.; Gupta, S.; Levenson, J.L.; Mahmood, A.; et al. An International Consensus Study of Neuroleptic Malignant Syndrome Diagnostic Criteria Using the Delphi Method. J. Clin. Psychiatry 2011, 72, 1222-1228. [CrossRef] [PubMed]

10. American Psychiatric Association. Diagnostic and Statistical Manual of Mental Disorders: DSM-5TM, 5th ed.; American Psychiatric Publishing, Inc.: Washington, DC, USA, 2013.

11. Masi, G.; Milone, A.; Viglione, V.; Mancini, A.; Pisano, S. Massive Asymptomatic Creatine Kinase Elevation in Youth During Antipsychotic Drug Treatment: Case Reports and Critical Review of the Literature. J. Child Adolesc. Psychopharmacol. 2014, 24, 536-542. [CrossRef] [PubMed]

12. Chun, T.H.; E Mace, S.; Katz, E.R. Evaluation and Management of Children With Acute Mental Health or Behavioral Problems. Part II: Recognition of Clinically Challenging Mental Health Related Conditions Presenting With Medical or Uncertain Symptoms. Pediatrics 2016, 138, e20161573. [CrossRef] [PubMed]

13. Goel, R.; Hong, J.S.; Findling, R.L.; Ji, N.Y. An update on pharmacotherapy of autism spectrum disorder in children and adolescents. Int. Rev. Psychiatry 2018, 30, 78-95. [CrossRef] [PubMed]

14. DeVane, C.L.; Charles, J.M.; Abramson, R.K.; Williams, J.E.; Carpenter, L.A.; Raven, S.; Gwynette, F.; Stuck, C.A.; Geesey, M.E.; Bradley, C.; et al. Pharmacotherapy of Autism Spectrum Disorder: Results from the Randomized BAART Clinical Trial. Pharmacother. J. Hum. Pharmacol. Drug Ther. 2019, 39, 626-635. [CrossRef] [PubMed]

15. Shafiq, S.; Pringsheim, T. Using antipsychotics for behavioral problems in children. Expert Opin. Pharmacother. 2018, 19, 1475-1488. [CrossRef] [PubMed]

16. Fung, L.; Mahajan, R.; Nozzolillo, A.; Bernal, P.; Krasner, A.; Jo, B.; Coury, D.; Whitaker, A.; Veenstra-VanderWeele, J.; Hardan, A.Y. Pharmacologic Treatment of Severe Irritability and Problem Behaviors in Autism: A Systematic Review and Meta-analysis. Pediatrics 2016, 137, S124-S135. [CrossRef] 
17. Wachtel, L.; Commins, E.; Park, M.; Rolider, N.; Stephens, R.; Réti, I. Neuroleptic malignant syndrome and delirious mania as malignant catatonia in autism: Prompt relief with electroconvulsive therapy. Acta Psychiatr. Scand. 2015, 132, 319-320. [CrossRef]

18. Ghaziuddin, N.; Hendriks, M.; Patel, P.; Wachtel, L.E.; Dhossche, D.M. Neuroleptic Malignant Syndrome/Malignant Catatonia in Child Psychiatry: Literature Review and a Case Series. J. Child Adolesc. Psychopharmacol. 2017, 27, 359-365. [CrossRef]

19. González-Romero, M.F.; Avina-Galindo, A.M.; Elbe, D.; Friedlander, R.; Vila-Rodriguez, F. Lifesaving Electroconvulsive Therapy for a Child With Autism Spectrum Disorder, Severe Self-Injurious Behavior, and Neuroleptic Malignant Syndrome. J. ECT 2019, 35, e55-e56. [CrossRef]

20. Thom, R.P.; McDougle, C.J. Case Reports: Clozapine for the Treatment of Catatonia in Autism Spectrum Disorder. J. Autism Dev. Disord. 2021. [CrossRef]

21. Cohen, D.; Bonnot, O.; Bodeau, N.; Consoli, A.; Laurent, C. Adverse Effects of Second-Generation Antipsychotics in Children and Adolescents. J. Clin. Psychopharmacol. 2012, 32, 309-316. [CrossRef]

22. Horikawa, M.; Ninomiya, M.; Nishi, M.; Ando, H.; Yamashita, Y.; Terasawa, K.; Katafuchi, Y. A ten-year-old autistic girl with neuroleptic malignant syndrome caused by neuroleptic agents. No Hattatsu. Brain Dev. 1989, 21, 486-490.

23. Murri, M.B.; Guaglianone, A.; Bugliani, M.; Calcagno, P.; Respino, M.; Serafini, G.; Innamorati, M.; Pompili, M.; Amore, M. Second-Generation Antipsychotics and Neuroleptic Malignant Syndrome: Systematic Review and Case Report Analysis. Drugs $R$ D 2015, 15, 45-62. [CrossRef]

24. Ghaziuddin, N.; Andersen, L.; Ghaziuddin, M. Catatonia in Patients with Autism Spectrum Disorder. Child Adolesc. Psychiatr. Clin. N. Am. 2020, 29, 443-454. [CrossRef]

25. Fink, M. Expanding the Catatonia Tent. J. ECT 2021, 37, 77-79. [CrossRef] [PubMed]

26. Benarous, X.; Raffin, M.; Ferrafiat, V.; Consoli, A.; Cohen, D. Catatonia in children and adolescents: New perspectives. Schizophr. Res. 2018, 200, 56-67. [CrossRef] [PubMed]

27. White, D.A.C.; Robins, A.H. An Analysis of 17 Catatonic Patients Diagnosed With Neuroleptic Malignant Syndrome. CNS Spectr. 2000, 5, 58-65. [CrossRef]

28. Jakobsen, K.D.; Bruhn, C.H.; Pagsberg, A.K.; Fink-Jensen, A.; Nielsen, J. Neurological, Metabolic, and Psychiatric Adverse Events in Children and Adolescents Treated With Aripiprazole. J. Clin. Psychopharmacol. 2016, 36, 496-499. [CrossRef]

29. Xu, Z.; Prasad, K.; Yeo, T. Progressive Encephalomyelitis with Rigidity and Myoclonus in an Intellectually Disabled Patient Mimicking Neuroleptic Malignant Syndrome. J. Mov. Disord. 2017, 10, 99-101. [CrossRef] [PubMed] 